\title{
Introduction
}

\section{The Urgency of Now}

\author{
Barbara Gemmill-Herren, Lauren E. Baker and \\ Paula A. Daniels
}

There has been no dearth of global reports published over the past decade on the failures of our current food systems. These reports clearly document how food systems are generating widespread degradation of land, water, and ecosystems, significant greenhouse gas emissions, major contributions to biodiversity losses, chronic overnutrition, malnutrition, and diet-related diseases, and livelihood stresses for farmers around the world.

A cohesive focus and consensus on the solutions and policies that will genuinely transform our existing food systems is still underdeveloped, much less taken up in food systems policy and practice. In this volume, a diverse group of contributing authors articulate the many cogent efforts to introduce a new economic paradigm that offers new opportunities and pathways: True Cost Accounting (TCA) in agriculture and food systems has the power and potential to catalyze the transformations needed to address our multiple and interconnected crises.

\section{Why TCA, Why Now?}

Behind all the food that we eat is a vast realm of unaccounted for interactions: the diversion of water from rivers; the extraction of nutrients from soil; the discharge of pollutants to air and water; the exaction of labor to grow, manage, pick, and package; the release of carbon dioxide to transport and deliver; and so on. When we shine a light on these interactions it becomes clear that a $99 \not$ hamburger costs all of us a lot more than the dollar placed by a consumer into the hands of a cashier. The singular focus of the business model that made cheap food possible overlooks the multiple costs to society related to suffering with or cleaning up pollution, the cost of social assistance or food charity for large segments of the population who are not paid enough to buy the food they grow, manage, pick, or package, and the public health costs from the dietrelated disorders that are a direct consequence of industrially created highly processed food, to name just a few. In the end, this "cheap" hamburger is extremely expensive, but most of the cumulative cost is borne by all of us as a global community. A central challenge is that the uninformed choices that we as consumers, as policymakers, and businesses make perpetuate the problem. 
TCA (sometimes referred to as "full" cost accounting; here, we use "true") provides a framework for systemic shifts across food systems. It allows for aggregation of information across affected economies and aspects of the food supply chain (production, processing, distribution, and retail). It intends to create transparency for regulatory decision-making that can realign subsidies in a more balanced direction. It facilitates broad engagement from farmers to consumers, bridging practice and policy. What sounds, on the surface, like a complicated tool relegated to accountants is ultimately a clarion call for a new economics of food and a new relationship with the land and the food that we eat, starting with a holistic view of a system out of balance and ending with a new approach to business and integrated reporting. As TCA enters our vocabulary, readers might find it helpful to turn to the glossary as developed by the Global Alliance for the Future of Food (Eigenraam et al., 2020).

\section{Holistic Framing}

True Cost Accounting: Balancing the Scale includes a review of the theoretical and ontological roots and tensions within prior systems of accounting for the "externalities" of agriculture and food systems: those impacts that are a direct result of system activities, but whose consequences and corrections are not borne by the original parties. The more recent evolution of TCA, extended beyond environmental economics and accounting to include social, human, and health aspects, is traced. What emerges strongly throughout many chapters of this book is the need for integrated systems-based framing, taking a holistic view of all interactions comprising a food system.

\section{Measurement and Metrics}

As we struggle to find ways to manage our food system for public and planetary health, we need different ways of measuring, which in turn lead to more inclusive and holistic metrics. Currently, our ability to trace economic flows that create negative or positive consequences across the food system is hampered by opacity, as inscrutable as a compressed line on a corporate ledger. It remains more profitable to damage the environment and negatively impact human health, than to protect either of these. Yet the resultant costs are not evident to citizens or consumers, who pay at least twice or three times: at the checkout; for their poor health; and in loss of biodiversity (as one example). The organic food sector has long sought to translate principles and standards into the labeling of food, giving price incentives for food produced in ways that add value to the public good ("Incentives to Change: The Experience of the Organic Sector").

Measuring costs—and benefits-is far from an exact science, with inherent uncertainties and approximations ("Incentives to Change: The Experience of the Organic Sector"). Developing values for what has not previously been measured involves the engagement of communities throughout food systems 
and across value chains, as clearly illustrated in Chapter 3 by the process of bringing people together to account for water use and costs in the Andes ("Upstream, Downstream: Accounting for the Environmental and Social Value of Water in the Andes"). It demands that we respect the diverse ways of assigning value, which have often been characterized through monetary units, but do not need to be. TCA is subject to the critique that it is another extension of neoliberal policies that unduly quantify nature, thus constraining a more comprehensive respect for its life-giving pricelessness. Monetary units reflect a current societal norm, but this book's authors argue that this is often a poor choice that can and should be reconsidered ("The Economics of Ecosystems and Biodiversity"). More holistic and inclusive measurements of value can consistently help to identify which pathway we are on when considering all food system impacts, whether in a positive or negative direction. In the search for universal application and local contextualization, a number of authors in this volume stress that the value of this realigned framework of measurement and metrics is to arrive at estimates that point us in the right direction, rather than (perhaps impossibly) striving for the exact or perfect information in finite degree ("From Practice to Policy: New Metrics for the 21st Century," "Harmonizing the Measurement of On-Farm Impacts").

The specific challenges of identifying "true" values are explored in many chapters of this book, in manifold ways, and there is wide agreement that TCA in agriculture and food systems should not be mistaken as a ploy to "put nature up for sale" ("Methods and Frameworks: The Tools to Assess Externalities," "The Economics of Ecosystems and Biodiversity"). In many places within this volume, authors reflect on how TCA's application can avoid the strictures of "financialization" of nature and other public goods. Salman Hussain from the United Nations Environment Programme emphasizes this point in his text box on the TEEBAgriFood Evaluation Framework. Incorporating tangible and intangible values is key to learning to manage the complexity of food systems, in transparent ways so that social and environmental considerations are made evident ("Upstream, Downstream: Accounting for the Environmental and Social Value of Water in the Andes"). Marta Echavarria and her co-author describe how traditional Indigenous water management practices represent intangible values and contextually important socially and culturally appropriate approaches. This demands that we-and our decision-makers-consider the implications of our choices across all four capitals (understood as ways of framing the various stocks that embody the streams of benefits contributing to human well-being).

The application of this approach is illustrated by Kathleen Merrigan in the questions that she asks about how we evaluate meat compared with plant-based or cellular alternatives ("Trade-Offs: Comparing Meat and the Alternatives"), showing the utility of TCA to illuminate the degree to which commonly held perceptions might not match with reality across all sectors of concern, thus revealing unanticipated impacts. For example, as noted in Chapter 16 ("TradeOffs: Comparing Meat and the Alternatives") somewhat ironically, when 
viewed through a holistic TCA framework, a wholesale shift to faux meat production might actually be viewed as a shift from farm to factory in the face of social push-back against factory farming ("Trade-Offs: Comparing Meat and the Alternatives").

Nadia El-Hage Scialabba and Carl Obst in Chapter 1 on metrics ("From Practice to Policy: New Metrics for the 21st Century") provide an eloquent argument for capturing such system-based perspectives in broad standardized assessment metrics that can facilitate progress toward local and global sustainability goals. The criteria that such metrics must meet are well detailed in this chapter. A key point is that far from being an accounting scheme, or an assessment exercise, TCA is inseparable from a call for collective action, to address the costs so revealed and build benefits for the public good.

Measurement needs to be sensitive to the goals of food systems transformation, and appropriate to the relevant communities and component parts, including the farmers, growers, abattoirs, packhouses, processors, financial institutions, distributors, and retailers all contributing to its overall health. As we are reminded in the Chapter 6, "Harmonizing the Measurement of On-Farm Impacts," in this immensely complex yet interconnected system, each component needs to be healthy to restore the overall system to full vitality, beginning with the earth's farms and pastures. In Chapter 8, "Transforming the Maize Treadmill: Understanding Social, Economic, and Ecological Impacts," featuring four different approaches to TCA of maize farming, it is striking to reflect on the broad range of biodiversity benefits and ecosystem services that one crop can generate, as well as how government policies that do not sufficiently support smallholder farmers can serve as an impediment to the flow of such services.

Yet in order for the application of TCA at each level to be successful, we must first agree on a common language, framework, and metrics ("Harmonizing the Measurement of On-Farm Impacts"). While recognizing different contexts and complexities, essentially everyone working on TCA within this volume notes the compelling need for finding common frameworks and approaches ("Transforming the Maize Treadmill: Understanding Social, Economic, and Ecological Impacts").

The challenges and intricacies of price and valuation come to the fore in a number of chapters. The ability, for example, of municipal institutions to increase their purchases to reflect key values (local economies, environmental sustainability, fair labor, animal welfare, and nutritional health) is hampered by the higher cost of food products that have been certified as having been produced through certified organic standards, fair trade, or human and equitable practices. Such socially and environmentally certified food products are priced closer to "true cost" than industrially produced food. However, the price premiums are difficult for a school district or public institution to bear within current budgetary constraints ("True Cost Principles in Public Policy: How Schools and Local Government Bring Value to Procurement"). Similarly, as explored in Chapter 13 on international policy venues for TCA ("International 
Policy Opportunities for True Cost Accounting in Food and Agriculture"), it is well documented that while most of the poor people around the world can afford an energy-sufficient (in terms of calories) diet, they cannot afford either a nutritionally adequate or a healthy diet. The cost of a nutritionally adequate diet is estimated to be about $60 \%$ higher than the cost of a diet that is only energy-sufficient. The cost of healthy diets-one that is both nutritionally adequate but also includes a more diverse intake of foods from several different food groups - costs five times that of a diet that is only energy-sufficient, evidence that the true cost of food has much to do with structural inequalities and income equity.

The development of such broad TCA assessment metrics, or a composite index, requires the participation of a range of actors, from innovative practitioners interacting with governmental representatives, health, finance, and economy experts, and farmers and food producers along the food value chain ("From Practice to Policy: New Metrics for the 21st Century," "Harmonizing the Measurement of On-Farm Impacts"). While a diversity of viewpoints and purposes will inform the development of TCA metrics, the authors of this volume argue that TCA's universal application, with local contextualization, could be facilitated through the development of internationally accepted benchmarks.

\section{Engagement Along the Food Value Chain}

This is undoubtedly an exciting and critical moment for TCA - a field on the cusp of greater recognition and harmonization across approaches, poised for wider uptake. Recognizing that our food system is economically entrenched and resistant to change in many respects, we have sought in this volume to highlight a number of levers that may be essential for engaging all actors along food value chains. True "costing" cannot be successful if it remains a niche idea. The question remains how to amplify and accelerate changes along the food value chain. The chapters in this book provide us with many intriguing sources of inspiration that we hope might serve as a motivation for actors to engage. A number of areas where the approach can impact (health, power and equity, risk, and investment, engagement of farmers, environmental health and governance) are highlighted below.

\section{Human Health and Consumer Concerns}

As TCA in agriculture and food has evolved, an important element has been the incorporation of health and consumer concerns. A good example of how TCA can be relevant to consumers is the presence of sugar in sodas. Sugarsweetened soda marketed aggressively to children is causally linked by public health officials to the alarming increase in obesity and diabetes among the youth of the world. Yet the purveyors of soda do not bear the medical costs of addressing the health problems that their products create. Who does? Most 
often, the public does, through the subsidized health care system. The medical costs are external to the price of the soda paid by the consumer and the profits received by the soda company. Yet they are a significant consequence of the transaction.

The centrality of health impacts to TCA is reflected in two chapters in this book. One provides a framework to understand the multiple channels of health impacts: occupational hazards, environmental contamination, contaminated/ unsafe/altered foods, unhealthy dietary patterns, and food insecurity ("Health Impacts: The Hidden Costs of Industrial Food Systems"). This chapter helps us to think systemically about health impacts and links them to the political economy of food systems. The other, through a deep dive into food and health implications in the USA, provides striking documentation of the costs of current diets and proposes several solutions and policy mechanisms. This chapter illuminates the fact that even in the face of strong evidence, there remain substantial individual and societal barriers to food system change, whose root causes (income constraints, systemic racism, political influence of the food and beverage industry, to name a few) need to be addressed ("The Real Cost of Unhealthy Diets").

\section{Power and Structural Inequities}

TCA, if it is to be transformative, must address issues of power and existing structural inequities in food systems that impose the greatest costs on the most vulnerable members of society. Historic injustices-colonization, slavery, and racism-have long led to extractive relationships between the Global North and Global South. Current economic structures are built in part on exploitative relationships with women and people of color. This demands that we scrupulously include issues of power and equity in our true cost frameworks. The case of maize in Malawi in Chapter 8 illustrates how historical injustice and power imbalances are at the root of much food policy and practice; through a singular focus on yields, without consideration of impacts on other social, human, and natural capital, power has been consolidated, and smallholders disenfranchised without achieving the stated aims of food and nutrition security ("Transforming the Maize Treadmill: Understanding Social, Economic, and Ecological Impacts").

Equally compelling is to understand how labor - in restaurants and along food value chains in general — has been deeply undervalued throughout history. One of the greatest blind spots in true costing is labor. Throughout food value chains, labor is poorly compensated, and people are often obliged to work under unsafe conditions - an issue that has only been amplified in fields and meatpacking plants during the coronavirus (COVID-19) pandemic. The occupational hazards faced by farmworkers, farmers, and smallholders the world over affect populations that are already vulnerable, owing to modest income levels. The service sector in the USA is one of the few industries in which the majority of labor costs are not actually reflected in the cost of the meal, but are 
expected to be paid in tips. The cultural changes needed to reverse these biases and cultural norms will take concerted education campaigns and policy measures, but at the same time, the pandemic and the global reckoning with race is "both the gravest crisis in the service sector's history in the United States and also the greatest moment for transformation-for building power among workers and change among employers toward a sustainable future of equity and collective prosperity" (see Chapter 17, "Dining Out: The True Cost of Poor Wages").

Several chapters make a strong case for building new compensation practices, creating new business models, and building the power of farmers, workers, and local communities through the application of TCA and resulting action.

\section{De-Risking the Future}

Risk is another theme underscored by authors in this volume-a compelling motivation for the engagement of the private sector. For many companies, it is the risk of supply chain disruptions owing to dependencies on natural, social, and human capital that brings them to focus on how they can build, rather than draw down these capitals ("From Practice to Policy: New Metrics for the 21st Century"). It is a challenge to introduce wholesale systems change through TCA to companies and institutional investors who logically seek enterprise or fund-level success. Addressing risk and risk exposure could have positive impacts at the enterprise/investment level and for food systems more broadly if the right metrics are considered ("Investing in the True Value of Sustainable Food Systems"). As noted in Chapter 14, "The Business of TCA: Assessing Risks and Dependencies Along the Supply Chain," although the importance of the state of nature, ecosystems, and employees for the success of companies is undeniable to the corporate sector, these impact drivers have not been sufficiently considered in quantitative risk management. Redefining risk, reward, efficiency, and the issue of scale to align with the systems approach of TCA is both a challenge and a potential game-changer ("Investing in the True Value of Sustainable Food Systems").

Chapter 14 ("The Business of TCA: Assessing Risks and Dependencies Along the Supply Chain") reminds us of the importance of looking beyond conventional food and agriculture stakeholders, as important as they are (farmers, food processors, markets, etc.) to those in the banking, finance, and insurance industries that can also drive change. If at present it is the general public-communities and taxpayers - who are paying for the negative externalities in our food system, the transformations required for our food systems to meet the synergistic needs of humans and nature will require those in investment and finance to understand and address such costs. The chapters on investment and supply chains note that a TCA assessment for those in the private sector must demonstrate benefits of better practices not only using sustainability language but in tangible financial terms and incorporate these in credit ratings, insurance policies, annual accounts, and company valuations ("The Business of TCA: Assessing Risks and Dependencies Along 
the Supply Chain" and "Investing in the True Value of Sustainable Food Systems"). In Chapter 15, a strong need is articulated for a common approach and metrics to measure impact and to have those metrics align with accounting standards ("Investing in the True Value of Sustainable Food Systems).

\section{Governance for the Public Good}

Societal support for TCA and the potential public good arising from this approach is critical at all levels of governance. This is illustrated in the chapters in this book that explore local ("True Cost Principles in Public Policy: How Schools and Local Government Bring Value to Procurement”), subnational ("Fostering Healthy Soils in California: Farmer Motivations and Barriers"), national ("Cotton in Egypt: Assisting Decision Makers to Understand Costs and Benefits," "The Economics of Ecosystems and Biodiversity"), and international levels ("International Policy Opportunities for True Cost Accounting in Food and Agriculture") of action. In Indonesia, for example, a TCA study carried out under the Economics of Ecosystems and Biodiversity (TEEB) framework convinced the government to include cacao agroforestry in their 2020 Five-Year Development Plan for Indonesia for the first time ("The Economics of Ecosystems and Biodiversity"). Exactly how governments can most effectively design and implement policy and programs to support TCA is still being explored. Although public policy responses to current health (and diet-related) crises are evolving with relative urgency, governments are often reluctant to regulate the private sector, even when the influence of both is paramount to dietary choices. As pointed out in Chapter 10, the real cost of unhealthy diets is often directed at consumers who can hardly be expected to counter the full weight of the food industry. A number of tools are available to the public sector, explored in this volume, including encouraging and rewarding various incentives ("Fostering Healthy Soils in California: Farmer Motivations and Barriers"), taxes and subsidies ("The Real Cost of Unhealthy Diets"), public procurement policies ("True Cost Principles in Public Policy: How Schools and Local Government Bring Value to Procurement"), and greater support for the organic sector ("Cotton in Egypt: Assisting Decision-Makers to Understand Costs and Benefits," "Incentives to Change: The Experience of the Organic Sector"). The multilateral system provides a number of entry points for governments to discuss and explore the implications of TCA. Given the complex and interconnected nature of the global food system, progress will require significant commitment on an international level as well ("International Policy Opportunities for True Cost Accounting in Food and Agriculture").

One concrete measure proposed here is for policymakers to embed TCA in decision-making as an administrative process, as seen in Chapter 12 ("Embedding TCA Within U.S. Regulatory Decision-Making”), as a way of assessing a country's stock flows through international trade, and as a means of monitoring international commitments, as seen in Chapter 13 ("International Policy Opportunities for True Cost Accounting in Food and Agriculture"). 
Illuminating the cost to society of negative externalities through TCA can be a way to rework this unintentionally reinforcing system, to re-order policy priorities and to bring the system back into balance by promoting and incentivizing the positive benefits of food systems when they are managed for health and sustainability.

\section{The Externalities of Farming, Positive and Negative}

TCA does not end with farmers, but it begins with them. As described in the "Harmonizing the Measurement of On-Farm Impacts," farms are the basis of all food systems, containing the key to their vitality. While industrial agriculture might be responsible for excessive use of toxic chemicals, pollution of waterways, and sterile soils, ecologically based farming systems are capable of minimizing or eliminating such inputs, restoring soil fertility, fostering diversity, and creating building resilience against the shocks anticipated with climate change, while producing nutritious food and providing a decent quality of life for farmers and farm workers. But none of this can be done in isolation; working with farmers to recognize these positive externalities is central to TCA in agriculture and food.

\section{True Cost Accounting as a Transparent Process}

Negative externalities are not new; they are a form of market failure that has existed as long as markets have existed. But current global economic structures, with vastly increased technological growth, international trade and the institutionalization of the price-based market model has led to a massive externalization of costs in food and agriculture, through the drive for higher shared public costs and lower food prices throughout the world ("True Price Store: Guiding Consumers"). The author of Chapter 18 ("True Price Store: Guiding Consumers") proposes that if true costs are the problem, true prices (the market price, together with added external costs) and transparency regarding both of these are the solution. Establishing what is "true" and how to measure it naturally has challenges but provides important opportunities to link to consumers, to highlight environmental impacts and human rights ("True Price Store: Educating Consumers"). It also provides scope for dialogue across value chains and for companies to communicate differently about their impacts, positive and negative. Chapter 9, "Fostering Healthy Soils in California: Farmer Motivations and Barriers," on building incentives for sound agricultural practices points to the disconnect between consumers and the producers and processors that, without ways to communicate more transparently, hamper the ability of consumers to make choices that internalize true costs. We are invited to see "true pricing" is as an activity rather than an analysis, as a decisionmaking process in which everyone can participate as a consumer, citizen, business owner, employee, investor, and policymaker ("True Price Store: Guiding Consumers"). 


\section{Conclusion}

As a whole, the chapters in this book point toward the potential for our food system to be more human centered than profit centered; and toward a food system that has a more respectful relationship with the planet. The authors outline a path forward based on TCA for food. This path seeks to broaden, expand, and fix our current food metrics, in policy and in practice, by applying a holistic lens that evaluates the actual costs and benefits of different food systems, as well as the impacts and dependencies between natural systems, human systems, and agriculture and food systems. Most importantly, this path acts upon this integrated understanding to create an economic system that respects true costs and results in a more balanced relationship with respect to its role in the world.

\section{References}

Eigenraam, M., McLeod, R., Sharma, K., Obst, C., \& Jekums, A. (2020). Applying the TEEB AgriFood Evaluation Framework. United Nations Environment Programme and IDEEA Group. 